\title{
Relapse of unusual localization of classic seminoma with post-chemotherapy transformation
}

\author{
Mayte Delgado Ureñaa ${ }^{1}$ Marta Legerén ${ }^{1}$, Fernando Gálvez ${ }^{1}$, Ana Villaescusa ${ }^{1}$, Jorge Aparicio ${ }^{2}$, \\ Jose M Jurado1, Isabel Blancas ${ }^{1}$, Maria J Sánchez ${ }^{1}$, Ana L Romera ${ }^{3}$, Ana P Martínez ${ }^{3}$, \\ Enoe Quiñonez ${ }^{4}$, Isabel Dulcey ${ }^{4}$, Jose L Puche ${ }^{1}$ \\ ${ }^{I}$ Medical Oncology Service, Hospital Clínico San Cecilio, Granada, Spain. \\ ${ }^{2}$ Medical Oncology Service, Hospital Universitario y Politécnico La Fe, Valencia, Spain. \\ ${ }^{3}$ General Surgery Service, Hospital Clínico San Cecilio, Granada, Spain. \\ ${ }^{4}$ Pathologic Anatomy Service, Hospital Clinico San Cecilio, Granada, Spain.
}

Received November 06, 2013; Revised December 14, 2013; Accepted December 17, 2013; Published Online January 03, 2014

\section{Case Report}

\begin{abstract}
Germ cell tumor is the most common cancer among males in the 20-39 year-old age range, representing 21\% of invasive cancer diagnose. The vast majority of testicular tumors in this age range are germ cell tumors. There are two types of malignant tumors, the pure seminoma cell and non-seminomatous germinal cell tumors (NGCT). We present the case of a patient who underwent a testicular tumor surgery, classic seminoma stage I, receiving two cycles of adjuvant carboplatin chemotherapy. During the follow up, an elevation on the alpha-fetoprotein level was observed, thus the final diagnosis was adenopatic recurrence of the Yolk Sac tumor.
\end{abstract}

Keywords: Classic Seminoma; Alpha-fetoprotein; Vitelline tumor

\section{Introduction}

Testicular tumors are the most common malign solid neoplasias affecting young males, representing less than $1 \%$ of male tumors. The number cases have a peak in the age range 20-39 years, then decline; therefore it is considered a prototypic malignancy of young adults. The incidence of germ cell tumors in males is relatively steady through the age range 20-39 years. From 2001 to 2005, the incidence of germ cell tumor in the US was estimated to be 11.8 per 100,000 males aged 20-39.1 years. Overall, there are about 8200 new cases of testicular germ cell tumor in the United States annually. ${ }^{1}$

There are two types of malignant tumors, the pure seminoma cell and non-seminomatous germinal cell tumors (NGCT). In clinical practice, three types of tumoral markers are quantified in blood analysis: alpha-fetoprotein, (AFP), beta

Corresponding author: Mayte Delgado Ureña; Hospital Clínico San Cecilio. Avda. Dr Oloriz s/n. 18006, Granada, Spain.

Email: maitechu22@hotmail.com

Cite this article as:

Urena MD, Legeren M, Galvez F, Villaescusa A, Aparicio J, Jurado JM, Blancas I, Sanchez MJ, Romera AL, Martinez AP, Quiñonez E, Dulcey I, Puche JL. Relapse of unusual localization of classic seminoma with post-chemotherapy transformation. Int J Cancer Ther Oncol 2014; 2(1):02016. DOI: 10.14319/ijcto.0201.6 subunit of chorionic gonadotropin, (hCG), and lactate dehydrogenase (LDH). Levels of AFP and/or hCG show an increase in $80-85 \%$ of the NGCTs, even in non-metastatic disease. However, the hCG is elevated in less than $20 \%$ of the seminoma cells and showing not AFP level increase in these tumors. ${ }^{2}$ Before the development of the effective chemotherapy, the 5-years survival rate in patients with germinal tumors was $64 \%$ whereas this was improved to the current $95 \%$ for seminoma cells and non-seminomatous cells.

After the initial treatment, the follow up must be carried out with periodic hCG and AFP determinations. An increase in tumoral markers represents the first evidence of disease, including those ones that have normal levels at the time of the initial diagnosis. ${ }^{3}$ Relapsed patients with pure seminoma stage-I after the orchiectomy can be treated with radiotherapy (RT) or cisplatine-based chemotherapy. ${ }^{4}$ In case of residual masses, patients must be only observed, except for tumors larger than $3 \mathrm{~cm}$, in this case, neoplasia removal will be performed or a biopsy if the surgery was not possible. Currently, positron emission tomography (PET) computed axial tomography application is recommended and if the outcome is positive (increased SUV) it is mandatory to remove the neoplasia. Relapsed patients with CGNT stage-I 
after an orchiectomy must be treated with cisplatine chemotherapy and underwent surgery of the residual masses, except in cases when the primary tumor was an embrionary carcinoma, with or without seminoma. Monitoring is recommended in patients under chemotherapy when the tumor volume decreased at least $90 \%$.

\section{Clinical case}

We report the case of one patient, a 45-years-old male, without relevant medical history, underwent for vasectomy, showed up at the emergency service in November 2011 for painless tumor in left testicle. Blood analysis was performed yielding the following results, human chorionic gonadotropin (hCG) level was $61 \mathrm{mU} / \mathrm{mL}$ (normal level $<5$ $\mathrm{mU} / \mathrm{mL}$ ), alpha-fetoprotein (AFP) level of $12 \mathrm{ng} / \mathrm{mL}$ (normal range: $0-10 \mathrm{ng} / \mathrm{mL}$ ) and $\mathrm{LDH}$ level of $494 \mathrm{U} / \mathrm{L}$ (normal range: $230-460 \mathrm{U} / \mathrm{L})$.

A surgery was performed, on November 18, 2011according to germinal tumor diagnosis by left inguinal orchiectomy. Anatomopatologic (AP) study shows a $4.8 \times 2.2 \mathrm{~cm}$ classic seminoma that invades both testicular membranes ( $22 \mathrm{NxMx})$ without linfovascular presentation and with resection borders free. The post-surgery analysis showed hCG 0.1 $\mathrm{mU} / \mathrm{mL}$, AFP $14 \mathrm{ng} / \mathrm{mL}$ and LDH $321 \mathrm{U} / \mathrm{L}$ levels. The thoracic and abdominal computed axial tomography showed no visceral or lymph node involvement.

Because of the type of tumor, a classic high risk testicular seminoma stage-I, (larger than $4 \mathrm{~cm}$ ) with good prognosis, the patient received two cycles of adjuvant carboplatin (AUC7) every 21 days, finishing on January 20, 2012, and followed by regular monitoring.

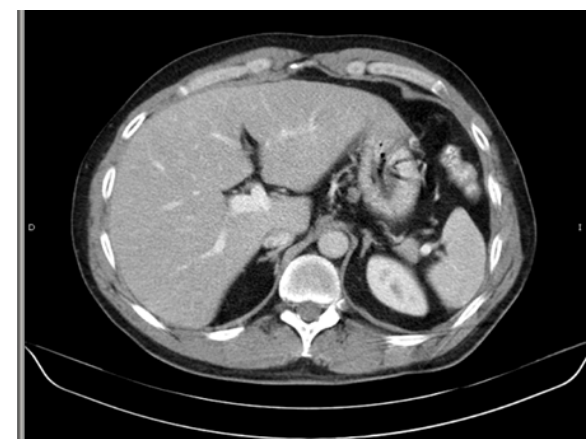

FIG. 1: Abdominal computed axial tomography May 2012: adenopathy of $8 \mathrm{~mm}$ in minor axis at high grastrohepathic level

On January 2012, the blood analysis showed an AFP increase (34.2 ng/mL). Due to this elevation, the patient was assessed closely. A re-evaluation was performed by clinical examination, thoracic and abdominal computed axial tomography, PET computed axial tomography, cranial RMN, lumbar puncture and bone marrow biopsy. The obtained outcomes could not explain the AFP increase. The primary tumor biopsy was reviewed by the Pathological Anatomy Service confirming the initial diagnosis of classic seminoma. On May 2012, the AFP showed a level of $107 \mathrm{ng} / \mathrm{mL}$ and the computed axial tomography showed an adenopathy of $8 \mathrm{~mm}$ of lower axe at the gastrohepatic high level, (Figure 1).

A High technology imaging in digestive endoscopy, (HDE), was implemented ed and no malicious adenopathies were noted. On July 2012, due to the rise of AFP, (2400 ng/mL), and in absence of macroscopic disease chemotherapy was started with BEP schedule (Cisplatin $20 \mathrm{mg} / \mathrm{m}^{2}$ days $1-5$, Etoposide $100 \mathrm{mg} / \mathrm{m}^{2}$ days $1-5$ and Bleomycin $30 \mathrm{mg}$ days 1 , 8 and 15) every 21 days during 3 cycles, AFP level was reduced to $350 \mathrm{ng} / \mathrm{mL}$. After two months of follow up, AFP level increased again and computed axial tomography showed an increase to $17 \mathrm{~mm}$ in the gastrohepatic adenopathy previsouly observed (Figure 2). On 14 February of 2013, the patient underwent a laparothomy showing an adenopathy at the celiac trunk $(2 \mathrm{~cm})$ in close contact with panchreas. The AP result was compatible with solid Yolk Sac Tumor, with a significant AFP expression. After lymph node metastasis surgical removal, AFP droped to $44.7 \mathrm{ng} / \mathrm{mL}$ level and two additional cycles of carboplatin and ethoposide were administered, currently the patient maintain this treatment.

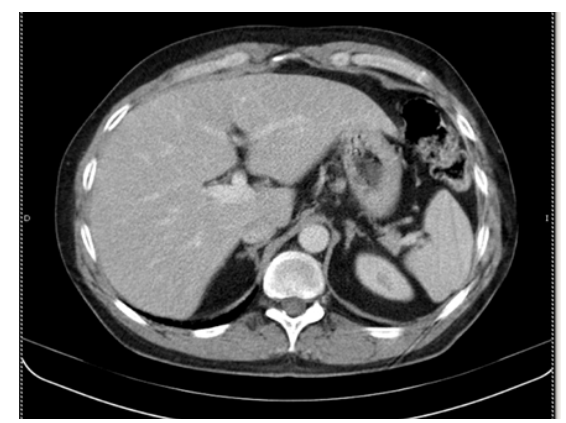

FIG. 2: Abdominal computed axial tomography January 2013: adenopathy of $17 \mathrm{~mm}$ in minor axis at high grastrohepathic level.

\section{Discussion}

In most cases of germinal tumors stage-I, a clinical follow up is performed. The recidives incidence is around $16-20 \%$ and the median of time is $12-18$ months, and the most common site is the retroperitoneum, followed by pelvic and lung lymph nodes. In contrast, in this patient, the radiological relapse happens at grastrohepatic level without other adenopathies at retroperitoneal level. Carboplatin has an effect in the metastatic seminoma, (although lower than cisplatin), and with an acceptable tolerability profile. Most of the patients with stage-I seminoma were treated with one or two cycles or adjuvant carboplatin obtaining excellent results. The relapse index achieved by treatment is smaller than after radiotherapy and the 5-years-survival rate is almost $100 \%$, therefore it is recommended in high-risk patients, (size greater than $4 \mathrm{~cm}$ or with Rete testis invasion). 5,6 
In this case, the minimum AFP elevation prior and after surgery, (12 and $14 \mathrm{ng} / \mathrm{mL}$ respectively), questioning the non-seminomatous nature of the tumor. Although, anatomopathological findings after over 10 histological slides in the primary testicular tumor showeded a classic pattern seminoma, (Figure 3), with clear lymphocitic infiltration and lack of pseudoglandular patterns.

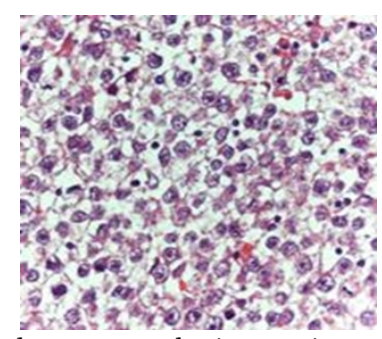

FIG. 3: Original tumor: classic seminoma with minimal lymphocitical infiltration.

The immunohistochemical analysis showed a classic immunophenotype with OCT3+and AFP-, cytokeratins- and hCG-. However, the ganglionar metastasis showed a different histology, showing a solid vitelline tumor with glandular areas, (Figure 4), the immunophenotype was completely different from the original tumor, being AFP + (Figure 5) and showing SALL4 expression.

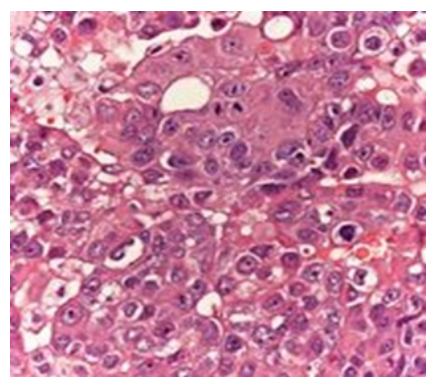

FIG. 4: Lymphatic ganglion: metastasis of vitelline tumor with solid pattern and in the glandular part. Observe hyaline globules.

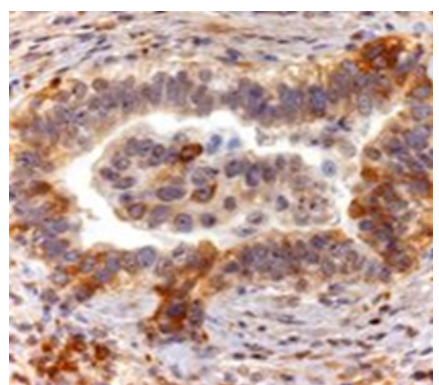

FIG. 5: Viteline tumor, glandular area with clear secretion of alpha-fetoprotein.

The classical conception that seminoma cannot evolve towards other tumoral types has been controversial, previous data showing the seminoma pluripotenciality with similar characteristic to primary germinal cells. This evidence is supported by immunohistochemical and ultra-structural studies that showed somatic differentiating aspects, (cytokeratin, blood antigens), in primitive germinal cells of the seminoma. This assumption is showed for both testicular and ovarian germinomas. ${ }^{7,8,9}$ This conversion from primary germinal cells is just a particular type of maturation process, in this case induced by chemotherapy or spontaneously.

\section{Conclusion}

The relapse of classic seminoma stage-I is rare and usually appears in retroperitoneum or lungs. In case of metastasis, the histology is similar to primary tumor but, occasionally, it can suffer cellular transformation, induced by chemotherapy. In other cases, the transformation occurs on the histology alone, without chemotherapy.

\section{Conflict of interest}

The authors declare that they have no conflicts of interest. The authors alone are responsible for the content and writing of the paper.

\section{References}

1. Hayes-Lattin B, Nichols CR. Testicular cancer: a prototypic tumor of young adults. Semin Oncol 2009; 36: 432-8.

2. Bower M, Rustin GJ. Serum tumor markers and their role in monitoring germ cell cancers of the testis. In: Textbook of Genitourinary Oncology, 2nd, Vogelzang NJ, Scardino PT, Shipley,WU, Coffey, DS (Eds), Lippincott, Williams and Wilkins, Philadelphia 2000 p931.

3. Fossa A, Fossa SD. Serum lactate dehydrogenase and human choriogonadotrophin in seminoma. Br J Urol 1989; 63:408.

4. Warde P, Gospodarowicz M. Evolving concepts in stage I seminoma. BJU Int 2009; 104:1357-61.

5. Von der Maase H, Specht L, Jacobsen GK, et al. Surveillance following orchiectomy for stage I seminoma of testis. Eur J Cancer 1993; 29A: 1931-4.

6. Germa-Lluch JR, Climent MA, Villavicencio H, et al. Treatment of stage I testicular tumours. Br J Urol 1993; 71: 473-7.

7. Srigley JR, Mackay B, Toth P, et al. The ultrastructure and histogenesis of male germ neoplasia with emphasis on seminoma with early carcinomatous features. Ultrastruct Pathol 1988; 12: 67-86.

8. Czaja JT, Ulbright TM. Evidence for the transformation of seminoma to yolk sac tumor, with histogenetic considerations. Am J Clin Pathol 1992; 97: 468-77.

9. Parkash V, Carcangiu ML. Transformation of ovarian dysgerminoma to yolk sac tumor: evidence for a histogenetic continuum. Mod Pathol 1995; 8: 881-7. 